\title{
Evaluation of antimicrobial activity of Curcumin against two oral bacteria
}

\author{
Najah A. Mohammed, Neama Y. Habil* \\ Medical technology institute, Medical technical university (MTU), Baghdad, Iraq
}

Email address:

Drneamahabil@gmail.com (N. Y. Habil)

\section{To cite this article:}

Najah A. Mohammed, Neama Y. Habil. Evaluation of Antimicrobial Activity of Curcumin Against Two Oral Bacteria. Automation, Control and Intelligent Systems. Special Issue: Artificial Nano Sensory System. Vol. 3, No. 2-1, 2015, pp. 18-21.

doi: 10.11648/j.acis.s.2015030201.14

\begin{abstract}
Oral pathogenic gram-positive bacteria, Streptococcus pyogenes (Strept.pyogenes) are caused severe human diseases with complications, including rheumatic fever, sepsis, severe soft-tissue invasion, and toxic-shock-like syndrome (TSLS). Whereas, Streptococcus mutants(Strept. mutans), described a key causative agent of caries and infective endocarditis. Therefore, the aim of this study was to evaluate the inhibitory effect of Curcumin on Strept. mutans and Strept.pyogenes growth in comparison with the antibiotic Ciprofloxacin using well diffusion method. Minimum Inhibitory Concentration (MICs) showed that curcumin-mediated growth inhibition of Strept. mutans and, Strept. pyogenes. Results showed that curcumin significantly inhibitedthe activity of Strept. mutans and Strept. pyogenes growth with inhibition zones, $9.7 \mathrm{~mm}$ and $10.2 \mathrm{~mm}$, respectively while the inhibition zone of Ciprofloxacin $15.52 \mathrm{~mm}$ to $13.4 \mathrm{~mm}$ against Strept. mutans, Strept. pyogenes respectively.The antimicrobial activity of curcumin on Strept. mutans and Strept. pyogenes growth suggests that the curcumin may be useful for controlling dental biofilms, subsequently dental caries formation. This study provides significant insights into the therapeutic effect of curcumin against pathogenic gram positive bacteria, suggesting its potential as an alternative therapy, and opens the way for further studies on identification of novel antimicrobial targets of curcumin.
\end{abstract}

Keywords: Curcumin, Antibacterial Activity, Minimum Inhibitory Concentration (MIC)

\section{Introduction}

Curcumin is the most explored of the so called curcuminoids, a family of chemo-preventive substances present in the spice, which increasingly being mentioned in health journals and scientific papers as research on it grows $(1,2,3)$. Recent studies suggest that it may help to ease digestive discomfort, reduce inflammation and hereby to increase resistance to disease (2). Oral pathogenic bacteria are involved in periodontal, vascular diseases(4), and respiratory infections(5). Researchers were found that the plant extracts have potential antimicrobial effects against microorganisms [6, 7]. The increasing failure of chemotherapeutics and antibiotic resistance on pathogenic microbial growth has led to the screening of new tools that have a potential antimicrobial activity [7,1]. Indeed, plants are natural sources of antibacterial agents. Plant-derived medicines have been a part of our traditional health care system, and the antimicrobial properties of plant derived compounds are well documented. Herbal medicines are more effective and less harmful as they have negligible side effects. They exhibit low mammalian toxicity and can be handled [9, 10]. In addition, antibiotics are sometimes associated with adverse effects on the host including hypersensitivity, immune-suppression and allergic reactions. Therefore, there is a significant demand to develop an alternative antimicrobial drugs for the treatments of infectious diseases from medicinal plants [11, 12]. Curcumin is the most abundant polyphenol present in the dietary spice turmeric. Turmeric powder, derived from the rhizome of Curcuma longa, which is associated to the Zingberiaceae family [13], commonly used as a spice, food preservative, and foodcoloring agent $[14,15]$. Curcumin $[1,7$-bis (4-hydroxy-3methoxyphenyl)-1, 6-heptadiene-3, 5-dione; Diferuloylmethane], a yellow bioactive pigment, is the major component of turmeric. The dried rhizome is a rich source of beneficial phenolic compounds known as the turmeric [16]. Curcumin described as prebiotic, which have beneficial effects on human health (17). Prebiotics and probiotics have diverse effects on human health $(1,19,20)$.Turmeric as a 
part of prebiotics has a long history for therapeutic use. It has been used for various purposes and through different routes of administration. It has been used topically on the skin for wounds, blistering diseases such as pemphigus and herpes zoster, for parasitic skin infections, and for acne. It has been used via oral administration for the common cold, liver diseases, urinary tract diseases, and as a blood purifier(3). For chronic rhinitis and coryza, it has been used via inhalation [21, 23]. Throughout the most important effects, curcumin had shown a wide spectrum of biological actions such as anti-inflammatory agents, thereby a wide range of pharmacological uses [24, 26]. The meta analysis data showed that the curcuminoids may be effective in controlling dental biofilms and dental cavity formations, suggested that turmeric extracts can be extensively used in the treatment premalignant lesions in oral cavity [27]. Turmeric can be used in relief from pain and bleeding of gingival in gingivitis and periodontitis, as colorant in pit and fissure sealant or in dental-plaque detection system. Chemopreventive activity of curcumin is observed when it is administered prior to, during, and after carcinogen treatment as well as when it is given only during the promotion/progression phase of colon carcinogenesis $[27,1]$. In this study,curcumin showed a potential effect on oral gram positive bacteria.

\section{Material and Methods}

\subsection{Curcumin Extraction}

The dried rhizomes of curcumin were crushed with pestle and mortar. The powder was weighed and extracted with methanol. They were soaked in the solvent for 3 days and then filtered with Whatman filter paper (pore size $0.2 \mu \mathrm{m}$ ). The residue of extraction was re extracted by soaking in the same solvent for three times. The combined filtrate was concentrated and weighed. The solvent was added to make final concentration of the extract as $100 \mathrm{mg} / \mathrm{ml}$; same amounts of extracts were used for further studies such as antibacterial activity, and minimum inhibitory concentration (MIC).

\subsection{Screening for Antibacterial Activity}

Firstly, oral bacteria isolated (from 56 saliva patients) suffering from careis and pharyngitis on mitis salivarius plus bacitracin medium and blood agar for Strept. mutans and Strept.pyogenes, respectively and identifiedby API-20 Strep. System (bioMérieux, France). Secondly, the antibacterial activity was determined by using micro well dilution methods,in addition to using the Kirby-Bauer method [29]. Bacterial cultures were first grown on nutrient broth at $37^{\circ} \mathrm{C}$ for 18-24 h, incubated till turbidity became equivalent to McFarland 0.5 turbidity standard was obtained. The inoculates of the particular bacteria were streaked on the Muller Hinton Agar(MHA) (Oxoid,UK) plates using a sterile swab in order to ensure a uniform thick lawn of growth following incubation. Wells of $6 \mathrm{~mm}$ in diameter were formed on Muller Hinton agar plates. The dried plant extract was dissolved in dimethylsulfoxide (DMSO) to assume a concentration of $30 \mathrm{mg} / \mathrm{ml}$. Wells were cut into the agar and filled with $75 \mu \mathrm{l}$ of the plant extracts and one well with (DMSO) as negative control. Inoculated plates were incubated at $37^{\circ} \mathrm{C}$ for $18-24 \mathrm{hrs}$, and resulting diameters of inhibition zones were measured.These studies were performed in triplicate for each plant extract. The diameter of the inhibition zone around each well was taken as a measure of antibacterial activity. The antibacterial activity results were expressed in term of the diameter of inhibition zone and $<9 \mathrm{~mm}$ zone was considered as inactive form; 9-12 $\mathrm{mm}$ as partially active form; while13-18 $\mathrm{mm}$ as active form and $>18 \mathrm{~mm}$ as very active form [30]. The mean and standard deviation of the diameter of inhibition zones were calculated.

\subsection{Determination of Minimum Inhibition Concentration (MIC) of the Extract}

The MIC was defined as the lowest concentration that completely inhibited the growth of microorganisms for 24 hours. Bacterial strains were grown overnight on MHA plates at $37^{\circ} \mathrm{C}$ before being used. The antimicrobial activity of extract was examined using the standard broth dilution method. The MIC was determined in MHA broth using serial two-fold dilutions of extract in concentrations ranging from 200 to $12.5 \%(\mathrm{~V} / \mathrm{V})$ initial bacterial inoculums of $10^{6}$ $\mathrm{CFU} / \mathrm{ml}$ and the time and temperature of incubation being 24 $\mathrm{h}$ at $37^{\circ} \mathrm{C}$, respectively. The MIC is the lowest concentration of antimicrobial agents that completely visually inhibits growth of the microorganisms. The MIC measurement was done in triplicate to confirm the value of MIC for each tested bacteria [31].

\subsection{Minimal Bactericidal Concentration (MBC)}

After MIC determination of the extract tested, aliquots of $50 \mu \mathrm{l}$ from all tubes in which no visible bacterial growth was observed were seeded in MHA plates and were incubated for $24 \mathrm{~h}$ at $37^{\circ} \mathrm{C}$. The $\mathrm{MBC}$ endpoint is defined as the lowest concentration of antimicrobial agent that kills $100 \%$ of the initial bacterial population. The number of plates without colonies was noted.

\subsection{Statistical Analysis}

Data were analyzed using analysis of variance (General Linear Model, Minitab version 16).

All means are presented with the appropriate standard deviation. Significance was set at the confidence intervals of0.05.

\section{Results and Discussion}

Herbal plants have a source of medicinal compounds since ancient times. Plant extracts are used in different systems of medicine for the treatment of various human ailments, and for treatment of viral and fungal infections [32]. The effects of plant extracts on bacterial growth have been investigated in different parts of the world. It has been suggested that 
aqueous and ethanolic extracts from plants are a potential source of antiviral, anticancer and antimicrobial agents. In the present work, the results showed that the antibacterial activity of turmeric plant.Curcumin exhibited very good antibacterial activities (zone of inhibition in $\mathrm{mm}$ ) against Strept. mutans and Strept. pyogenes. The extract of curcumin was effective in inhibiting the two pathogenic bacteria with zone of inhibition, $9.7 \mathrm{~mm}$ and $\mathrm{mm} 10.2$ against Strept. mutans, Strept. pyogenes, respectively. While, the inhibition zone of Ciprofloxacin $15.52 \mathrm{~mm}$ to $13.4 \mathrm{~mm}$ against Strept. mutans, Strept. pyogenes respectively table (1) and (Figure 1, 2).

Table 1. Inhibition zone ( $\mathrm{mm}$ ) of methanolic extract of Curcumin againstStrept. mutans\& Strept.pyogenes compared with Ciprofloxacin.

\begin{tabular}{lll}
\hline Agent or inhibitor & Strept. mutans & Strepto. pyogenes \\
\hline Curcumin & $9.7 \pm 2.7^{*}$ & $10.2 \pm 2.1$ \\
Ciprofloxacin & $15.52 \pm 3.10$ & $13.4 \pm 3$ \\
\hline
\end{tabular}

The mean of inhibition zone $\mathrm{mm} \pm \mathrm{SD}, *$ significant at $\leq 0.05$

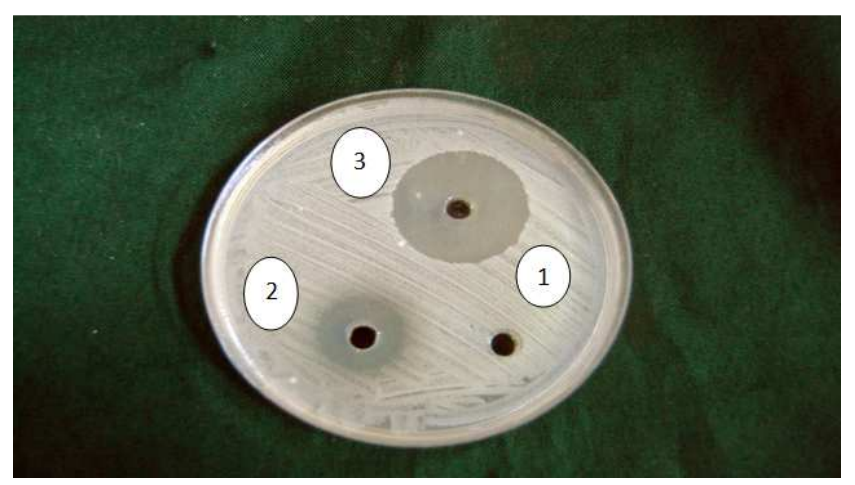

Figure 1. Inhibition zone ( $\mathrm{mm}$ ) of curcumin extract againstStrept. mutans compared with Ciprofloxacin. $1=$ negative control, $2=$ curcumin. $3=$ Ciprofloxacin.

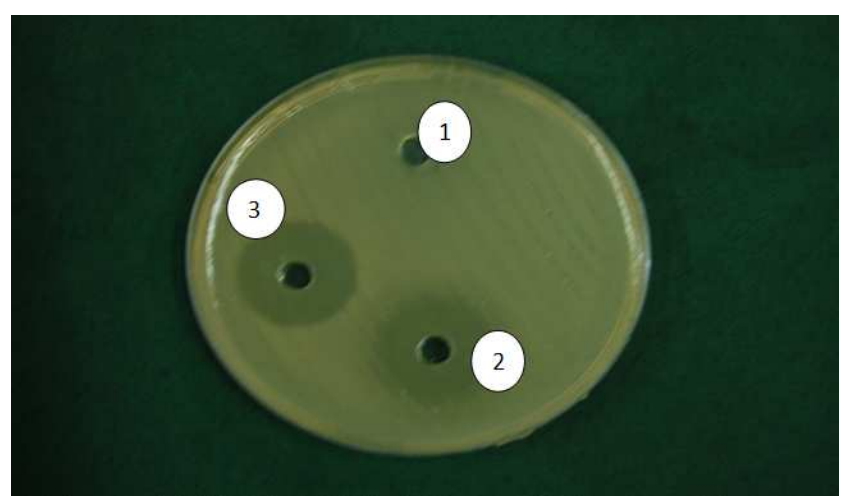

Figure 2. Inhibition zone (mm) of curcumin extract againstStrept. pyogenes compared with Ciprofloxacin. $1=$ negative control. $2=$ curcumin. $3=$ Ciprofloxacin.

It is interesting to annotation that $\mathrm{G}+\mathrm{ve}$ bacterial isolates were sensitive tocurcuminextract.Present study is in agreement with Chattopadhyay et.al who reported thatcurcumin extract produce antibacterial activity against a broad range of microbes and especially $\mathrm{G}+\mathrm{ve}$ strains and multiple antibiotic resistant bacteria. These results, also correlates with Shahi et.al who reported that curcumin exhibited potent growth inhibitory effect against Grampositive bacteria,(Staph. aureus and Strep.mutans), Gram negative (E. coli and P.aeruginosa) and pathogenic yeast $C$. albicans.

During extraction process, solvents diffuse into the solid plant material and soluble compounds of similar polarity .The polarity of solvent affects quantity and composition of secondary metabolite of an extract. Traditional healers primarily use water for extract preparation from plant extracts but organic solvents have been found to give more consistent antimicrobial activity compared to water extracts [33]. The antimicrobial activities of this plant have already been studied with different microorganisms.

\section{References}

[1] Chen, Y. R. \& Tan, T. H. (1998). Inhibition of the c-Jun Nterminal kinase (JNK) signaling pathway by curcumin. Oncogene, 17, 173-178.

[2] Han, K.-H., Azuma, S. \& Fukushima, M.( 2014). In vitro fermentation of spent turmeric powder with a mixed culture of pig faecal bacteria. Food \& Function.

[3] Anand, P., Thomas, S. G., Kunnumakkara, A. B., Sundaram, C., Harikumar, K. B., Sung, B., Tharakan, S. T., Misra, K., Priyadarsini, I. K., Rajasekharan, K. N. \& Aggarwal, B. B.( 2008). Biological activities of curcumin and its analogues (Congeners) made by man and Mother Nature. Biochemical Pharmacology, 76, 1590-1611.

[4] Beck, J., Garcia, R., Heiss, G., Vokonas, P. S. \& Offenbacher, S.( 1996). Periodontal Disease and Cardiovascular Disease. Journal of Periodontology, 67, 1123-1137.

[5] Scannapieco, F. A. (1999). Role of Oral Bacteria in Respiratory Infection. Journal of Periodontology, 70, 793-802.

[6] Kafaru E. (1994) Immense Help Formative Workshop. In: Essential. Pharmacology, 1st edn. pp.11-14. Elizabeth Kafaru Publishers, Lagos, Nigeria. 125.

[7] Jason M. Tanzer, Streptococcus salivarius FruA Inhibits Streptococcus mutans biofilm formation. Journal of Dental Research vol.74, pp:1536 (1995).

[8] Jones, G., and Moellering R.C. (2004) Increasing antibiotic resistance among methicillin-resistant Staphylococcus aureus strains. Clin. Infect. Dis . 46 Suppl 5: 360-367.

[9] Evans, C.E., A. Banso and O.A. Samuel. (2002) Efficacy of some medicinal plants against Salmonella typhi: an in vitro study. J. Ethnopharmacology.80:21-24.

[10] Ahmad I, Mehamood Z, Mohammad F. (1998). Screening of some Indian medicinal plants for their antimicrobial properties. J. Ethnopharmacol. 62: 183-193.

[11] Clark A.M. (1996). Natural products as resource for new drugs. Phar. Res., 13:1133-1141.

[12] Cordell G.A.(2009).Biodiversity and drug discovery a symbiotic relationship. Phytochemistry, 55:463-480.

[13] Chattopadhyay I, Biswas K, Bandyopadhyay U, Banerjee RK (2004).Turmeric and curcumin: Biological actions and medicinal applications.Curr. Sci. 87: 44-53. 
[14] Aggarwal BB, Sundaram C, Malani N, Ichikawa H (2007). Curcumin: the Indian solid gold. Adv. Exp. Med. Biol. 595: 175. Brooks GF.

[15] Di Mario F, Cavallaro LG, Nouvenne A, Stefani N, Cavestro GM, Lori V, Maino M, Comparato G, Fanigliulo L, Morana E, Pilotto A, Martelli L, Martelli M, Leandro G, Franze A (2007). A curcumin-based 1-week triple therapy for eradication of Helicobacter pylori infection: something to learn from failure? Helicobacter, 12: 238-243. [IVSL].

[16] Menon VP, Sudheer AR (2007). Antioxidant and antiinflammatory properties of curcumin. Adv. Exp. Med. Biol. 595: 105-125.

[17] Panesar, P. S., Kumari, S. \& Panesar, R. (2013). Biotechnological approaches for the production of prebiotics and their potential applications. Critical Reviews in Biotechnology, 33, 345-364.

[18] Habil, N., Abate, W., BEAL, J. \& Foey, A. D. (2012). Lactobacillus casei strain Shirota selectively modulates macrophage subset cytokine production. Int. J. Probiotics \& Prebiotics 7(1), 1-12.

[19] Habil, N., Abate, W., BEAL, J. \& Foey, A. D. ( 2011). Probiotic bacterial strains differentially modulate macrophage cytokine in a strain-depent and cell subset-specific manner. Beneficial Microbe, 2(4), 283-293.

[20] Habil, N., Abate, W., BEAL, J. \& Foey, A. D. (2014). Heatkilled probiotic bacteria differentially regulate colonic epithelial cell production of human $\beta$-defensin-2: dependence on inflammatory cytokines. Beneficial Microbes, 5, 483-495

[21] Eigner D, Scholz D. (1999). Ferula asa-foetidaand Curcuma longa in traditional medical treatment and diet in Nepal. J Ethnopharmacol. 67:1-6.

[22] Majeed M, Badmaev V, Shivakumar U, Rajendran R. (1995).Curcuminoids Antioxidant Phytonutrients. Nutriscience Publishers, Inc. Pisctway New Jersey USA.

[23] Chattopadhyay I., Biswas K., Bandyopadhyay,U. and Banerjee R.K.(2004). Turmeric and curcumin: Biological actions and medicinal applications. Curr. Sci., 87: 44-53.

[24] Mohammadi K, Thompson KH, Patrick BO, Storr T, Martins
C, Polishchuk E, Yuen VG, McNeill JH, Orvig C (2005). Synthesis and characterization of dual function vanadyl, gallium and indium curcumin complexes for medicinal applications. J. Inorg. Biochem. 99: 2217-2225.

[25] Kawamori T, Lubet R, Steele VE, Kelloff GJ, Kaskey RB, Rao CV, Reddy BS. (2009).Chemopreventive Effect of Curcumin, a Naturally Occurring Anti-Inflammatory Agent, during the Promotion/Progression Stages of Colon Cancer. Cancer Res; 59:597-601.

[26] Bansod S., and Rai M.(2009). Antimicrobial Activity of Essential Oils from Indian Medicinal Plants against Human Pathogens. World Journal of Medical Sciences, 3 (2): 81-88.

[27] Pandit, Santosh; Kim, Hye-Jin; Kim, Jeong-Eun; Jeon, JaeGyu (2011). Separation of an effective fraction from turmeric against Streptococcus mutans biofilms by the comparison of curcuminoid content and anti-acidogenic activity. Food Chemistry 126 (4): 1565-70.

[28] Hadacek F and Greger H. (2007). Testing of antifungal natural products: methodologies, comparability of results and assay choice. Phytochem. Analys. 11: 137-147.

[29] Bauer, A. W.; Kirby, M (1966). Antibiotic Susceptibility testing by standard disc method. Am. J. Clin. Patho. 10, 45; 493-496.

[30] Junior, A. and Zanil, C. (2006). Biological screening of Brazilian meditional plants. Braz. J. Sci. 95: 367-373.

[31] CLSI, (2009). Methods for dilution of antimicrobial susceptibility tests for bacteria that grow aerobically. Approved standard 5th ed. CLSI document; M07-A8. (ISBN 1-56238-689-1).

[32] Shahi, S. K., Shukla, A. C., Bajaj, A. K., Banerjee, U., Rimek, D., Midgely, G., and Dikshit, A. (2000). Broad spectrum herbal therapy against superficial fungal infections.SkinPharmacolAppl Skin Physiol. 13(1):60-64.

[33] Qa'dan, F. Thewaini, A. Ali D. Afifi R, Elkhawad A. and . Matalka KZ. (2005). The antimicrobial activities of Psidiumguajava and Juglansregia leaf extracts to acnedeveloping organisms. The American Journal of Chinese Medicine, 33: 197-204. 